\title{
Análise Biomecânica dos Efeitos da Crioterapia no Tratamento da Lesão Muscular Aguda
}

\author{
Biomechanical Analysis of the Cryotherapy Effects in the Treatment of \\ Acute Muscular Injury
}

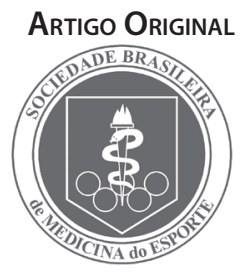

João Paulo Chieregato Matheus Juliana Goulart Prata Oliveira Milani' Liana Barbaresco Gomide

José Batista Volpon

Antônio Carlos Shimano'

1. Departamento de Biomecânica, Medicina e Reabilitação do Aparelho Locomotor, Faculdade de Medicina de Ribeirão Preto, Universidade de São Paulo (USP), Ribeirão Preto, SP.

Endereço para correspondência: Juliana Goulart Prata de Oliveira Laboratório de Bioengenharia Avenida Bandeirantes, 3900 Rua Pedreira de Freitas, casa 1 Campus da USP - Ribeirão Preto, SP CEP 14049-900

Telefone: (16) 3633-3063

E-mail: juliana.gpo@gmail.com; jugular@terra.com.br

Submetido em 26/11/2007 Versão final recebida em 09/02/2008 Aceito em 22/02/2008

\begin{abstract}
RESUMO
A crioterapia é amplamente utilizada por atletas profissionais e amadores no tratamento agudo de lesões musculares. Este trabalho teve como objetivo analisar as propriedades mecânicas do músculo gastrocnêmio lesionado por impacto direto e tratado com crioterapia. Para tanto, foram utilizadas 24 ratas Wistar, divididas em três grupos experimentais: grupo controle (C): animais mantidos em gaiolas-padrão por seis dias; grupo lesionado (L): animais submetidos à lesão por mecanismo de impacto no gastrocnêmio, sem tratamento e mantidos em gaiolas-padrão por seis dias; grupo lesionado e tratado com crioterapia (LC): animais submetidos à lesão, tratados com uma sessão de crioterapia, imediatamente após a lesão e mantidos em gaiolas-padrão por seis dias. Após essas etapas, os animais foram submetidos à eutanásia para que fossem realizados os ensaios mecânicos de tração dos músculos gastrocnêmios direitos, na máquina universal de ensaios (EMIC ). A partir dos gráficos carga versus alongamento de cada ensaio, foram calculadas as seguintes propriedades mecânicas: carga no limite máximo (CLM), alongamento no limite máximo (ALM) e rigidez (R). No ALM, o grupo $C$ apresentou diferença estatística $(p<0,05)$ somente quando comparado com o L. Quando analisadas carga máxima e rigidez, houve diferença estatística $(p<0,05)$ nos três grupos. Assim, enquanto os músculos lesionados sem tratamento apresentaram diminuição de todas as propriedades mecânicas analisadas, os tratados com crioterapia mostraram melhora das propriedades, porém, sem alcançar o grupo controle. Dessa forma, podemos concluir que a sessão de crioterapia por imersão imediata após a lesão promoveu melhora das propriedades mecânicas analisadas.
\end{abstract}

Palavras-chave: lesões de tecidos moles, músculo esquelético, crioterapia, ratos.

\begin{abstract}
Cryotherapy is widespread used in the acute treatment of muscle injuries of professional and unprofessional athletes. The purpose of this study was the investigation of mechanical properties of gastrocnemius muscle submitted to a impact mechanism of injury and treated with cryoterapy. Therefore, twenty four female Wistar rats were divided into three groups: Control (C): animals housed in standard cages for six days; Lesion (L): animals submitted to a direct impact mechanism of injury in the gastrocnemius muscle, without any treatment and kept into standard cages during six days; Lesion e cryotherapy (LC): animals submitted to the contusion, treated with a single session of cryotherapy immediately after lesion and housed in standard cages during six days. After those protocols, the rats were killed and their right gastrocnemius muscle were dissected and submitted to a mechanical test of traction in a universal assays machine (EMIC*). From the load versus elongation curves, the following mechanical properties were obtained: Maximum limit load (MLL), maximum limit elongation (MLE) and stiffness (St). There was a statistically difference between all groups in MLL and St. However, in the MLE there was statistically difference only between groups $C$ and $L(p<0,05)$. The results showed that the muscle contusion without treatment led to exasperation of all analyzed mechanical properties. Conversely, cryotherapy improved the muscle properties, although they had not reached the control group values. It can be concluded that the cryotherapy applied immediately after muscle contusion improved the muscle mechanical properties.
\end{abstract}

Keywords: soft tissue injuries, muscles, skeletal, cryotherapy, rats.

\section{INTRODUÇÃO}

A crioterapia é uma modalidade terapêutica freqüentemente utilizada no tratamento de lesões musculoesqueléticas agudas ${ }^{(1-6)}$. Traumas moderados e graves nos tecidos moles estão presentes na maior parte das lesões causadas por esportes recreacionais e competitivos $^{(7-8)}$. 0 tecido muscular esquelético é o mais afetado nesses tipos de traumas e a maior incidência de lesões musculares em humanos é decorrente, principalmente, de contusões produzidas por mecanismo de impacto ${ }^{(9)}$.
A lesão muscular é caracterizada por uma série de fatores, tais como desorganização das miofibrilas, ruptura de mitocôndria e retículo sarcoplasmático, interrupção da continuidade do sarcolema, autodigestão e necrose celular (10-11), além de disfunção microvascular progressiva e inflamação local|(6).

Apesar de o insulto primário não poder ser influenciado terapeuticamente, o crescimento secundário da lesão pode ser amenizado com certas intervenções, tais como frio local(2), imobilização tempo- 
rária, administração de drogas analgésicas e antiinflamatórias ${ }^{(8,12)}$. Há evidências de que a crioterapia produz efeitos analgésicos e promove a restauração estrutural e funcional, o que favorece o processo de reabilitação ${ }^{(2)}$. Dessa forma, a crioterapia local pode facilitar a recuperação de tais lesões, sendo que a vasoconstrição induzida pelo frio reduz a formação de edemas ${ }^{(5)}$, bem como a intensidade do dano celular local, por meio da redução do quadro hemorrágico(4) e das demandas metabólicas no tecido lesado(1).

Embora freqüentemente utilizada em programas de fisioterapia ${ }^{(13)}$, os efeitos da crioterapia no tratamento de lesões musculares agudas não estão totalmente elucidados ${ }^{(14)}$. Análises referentes ao estudo das propriedades mecânicas musculares são relevantes, pois os músculos esqueléticos são dotados de propriedades que influenciam seu comportamento frente à imposição de cargas, o que pode determinar a ocorrência ou agravamento de uma lesão ${ }^{(15)}$. Sendo assim, o conhecimento das características de resistência de alguns materiais é importante na medicina ortopédica e esportiva, pois os materiais biológicos, tais como músculo, osso, tendão e cartilagem, muitas vezes, necessitam de otimização de suas resistências para evitar rupturas ${ }^{(16)}$.

Considerando a escassez de pesquisas referentes a esse assunto, cuja análise seja direcionada ao estudo de propriedades mecânicas musculares por meio de ensaios mecânicos, este trabalho propôs investigar os efeitos de uma única sessão de crioterapia, aplicada imediatamente após lesão por mecanismo de impacto direto, nas propriedades mecânicas do músculo gastrocnêmio de ratas, após uma semana de trauma.

\section{MÉTODOS}

\section{Animais}

Para o desenvolvimento deste estudo, foram utilizadas 24 ratas fêmeas, Rattus norvegicus albinus, variedade Wistar, provenientes do Biotério Central da Prefeitura do Campus de Ribeirão Preto, da Universidade de São Paulo (USP). Durante os protocolos experimentais, os animais foram mantidos em gaiolas coletivas, em número máximo de três por gaiola, no Biotério do Laboratório de Bioengenharia da Faculdade de Medicina de Ribeirão Preto-USP. As ratas foram mantidas à temperatura ambiente controlada de $25^{\circ} \mathrm{C}$, fotoperíodo de $12 \mathrm{~h}$ claro/12h escuro, recebendo água e alimentação padrão ad libitum. Todos os procedimentos aos quais os animais foram submetidos estão de acordo com o International Guiding Principles for Biomedical Research Involving Animals ${ }^{(17)}$.

\section{Grupos experimentais}

Os animais foram distribuídos aleatoriamente em três grupos experimentais:

Grupo controle (C): composto por oito animais mantidos em gaiolas-padrão por seis dias.

Grupo lesionado (L): formado por oito animais submetidos à lesão por mecanismo de impacto no músculo gastrocnêmio direito, sem tratamento e mantidos em gaiolas-padrão durante seis dias.

Grupo lesionado e tratado com crioterapia (LC): constituído de oito animais com o músculo gastrocnêmio direito lesionado, tratados com uma sessão de crioterapia, imediatamente após a lesão, e mantidos em gaiolas-padrão por seis dias.

\section{Protocolo de lesão experimental aguda}

Para realização do protocolo de lesão experimental, foi utilizado um aparelho proposto inicialmente por Stratton et al.(18) e confeccionado por Oliveira ${ }^{(19)}$, com o intuito de provocar lesão por impacto direto em ratos. O equipamento consiste de duas hastes metálicas, com diâmetro de $10 \mathrm{~mm}$, estabilizadas por uma barra superior perpendicular. Essas hastes são fixadas a uma base plástica, na qual é acoplada uma base metálica retangular de $12,25 \mathrm{~cm}^{2}$, que serviu para posicionamento do membro pélvico do animal e apoio à queda livre da carga ${ }^{(19-20)}$.

Para realização da lesão por mecanismo de impacto direto, os animais foram anestesiados com associação de cloridrato de quetamina $(80 \mathrm{mg} / \mathrm{kg})$ e cloridrato de xilazina $(15 \mathrm{mg} / \mathrm{kg})$, na dose de $0,6 \mathrm{ml}$ da mistura para cada 100 gramas de massa corporal(21). Em seguida, o terço médio do gastrocnêmio do membro pélvico direito dos animais foi tricotomizado e posicionado sobre a base metálica do equipamento, estando o animal em decúbito ventral, com extensão de articulações de quadril, joelho e $90^{\circ}$ de dorsoflexão de tornozelo(19-20).

Para dirigir a queda livre do peso e possibilitar que a contusão ocorresse sempre na mesma região, a carga liberada foi conduzida por um guia de acrílico transparente e por um fio, fixado sobre o peso e lançado centralmente, por meio de uma roldana acoplada à barra superior do equipamento(20).

Conforme metodologia descrita em outros trabalhos, foi estabelecida uma carga de 200 gramas, liberada de 30 centímetros de altura, diretamente sobre o músculo gastrocnêmio das ratas, de modo a produzir uma força de impacto no sítio da lesão de, aproximadamente, 294 newtons ${ }^{(19-20,22)}$. Os animais foram submetidos a um trauma único e separados, conforme seu grupo experimental.

\section{Protocolo de crioterapia}

Imediatamente após a produção da lesão muscular aguda, os animais do grupo LC, ainda sob efeito da anestesia, foram submetidos a uma sessão única de crioterapia. Para tanto, a técnica de crioterapia foi executada por meio de imersão completa do membro pélvico lesionado em água, com temperatura média de seis graus Celsius, por 30 minutos. Como os animais estavam anestesiados, não houve dificuldade na manutenção da posição, que foi realizada manualmente, sem necessidade de quaisquer aparatos. Durante a aplicação da crioterapia, a temperatura foi acompanhada com o auxílio de um termômetro; assim que observadas alterações na temperatura preconizada, ela foi mantida com a colocação ou retirada de cubos de gelo.

\section{Preparação do músculo gastrocnêmio}

Passados seis dias do início do experimento, os animais foram submetidos à eutanásia, por administração intraperitonial de dose excessiva do anestésico tiopental sódico, a fim de possibilitar a retirada do músculo gastrocnêmio do membro pélvico direito. Para tanto, foi realizada a remoção da pele e de algumas partes moles, seguida da desarticulação do tornozelo e quadril. Para fixação da peça à maquina de ensaios, foram preservadas origem e inserção ósseas. Após a dissecação, as peças foram colocadas em solução de lactato de Ringer até o momento da realização dos ensaios, que ocorreu em tempo máximo de 30 minutos $^{(21)}$.

\section{Ensaio mecânico de tração}

Para realização do ensaio mecânico de tração longitudinal do músculo gastrocnêmio, foi utilizada uma máquina universal de ensaios (marca EMIC, modelo DL10000), do Laboratório de Bioengenharia, da Faculdade de Medicina da USP de Ribeirão Preto. Esta máquina foi equipada com uma célula de carga de $50 \mathrm{kgf}$ e interface direta a um microcomputador, com o software Tescं, responsável pelo comando do equipamento e plotagem do gráfico carga versus alongamento de cada ensaio. 
No momento do ensaio, o músculo gastrocnêmio do membro pélvico direito foi acoplado à máquina e, conforme metodologia estabelecida pelo laboratório, foi aplicada uma pré-carga de 200 gramas, durante o tempo de acomodação de 30 segundos, com o intuito de provocar acomodação do sistema. Após a pré-carga, o ensaio prosseguiu com velocidade preestabelecida de $10 \mathrm{~mm} / \mathrm{minuto}$ e a carga aplicada foi registrada pelo software em intervalos regulares de alongamento, até a ruptura muscular.

Os dados referentes à curva de cada ensaio foram transcritos para o programa Microsoft Excel 2000, no qual foram construídos os gráficos carga versus alongamento, nos quais identificamos duas fases: elástica (em que carga e alongamento são proporcionais e, se retirada a carga, o material volta às condições iniciais) e plástica (na qual carga e alongamento perdem a proporcionalidade e a deformação do material é irreversível, ou seja, há perda de sua integridade estrutural). A partir dos gráficos foram determinadas e analisadas as seguintes propriedades mecânicas:

- Carga no limite máximo (CLM): registro máximo de carga imposta, antes da ruptura muscular. É representada em newtons (N).

- Alongamento no limite máximo: alongamento máximo atingido pelo músculo, antes de sua ruptura. É representado em metros (x $\left.10^{-3} \mathrm{~m}\right)$.

- Rigidez (R): propriedade obtida na fase elástica, sendo determinada pela tangente da reta traçada nesta fase. É expressa em newtons/ metro $(\mathrm{N} / \mathrm{m})$

\section{Análise estatística}

A análise estatística foi realizada por meio do programa Instat ${ }^{\circledR} \mathrm{V}$. 3.00, da Graphpad Software. Foi realizado o teste de normalidade de Kolmogorov-Smirnov. Para análise simultânea dos grupos, foi utilizado o teste ANOVA e, para comparação entre os grupos, o teste de Turkey-Kramer, ambos com níveis de significância preestabelecidos de $5 \%(p<0,05)$.

\section{RESULTADOS}

Foram submetidos ao ensaio mecânico 24 músculos, sendo os valores expressos em médias e desvios-padrão para cada uma das propriedades dos três grupos analisados.

\section{Carga no limite máximo (CLM)}

Os grupos C, L e LC apresentaram, respectivamente, carga no limite máximo de 31,53 $\pm 2,95 \mathrm{~N} ; 17,99 \pm 2,65 \mathrm{~N}$ e 25,88 $\pm 2,34 \mathrm{~N}$ (gráfico 1).

Foi observada diferença estatística entre os três grupos: $C$ e $L$ ( $p<$ $0,001)$; C e LC $(p<0,01)$; L e LC $(p<0,001)$.

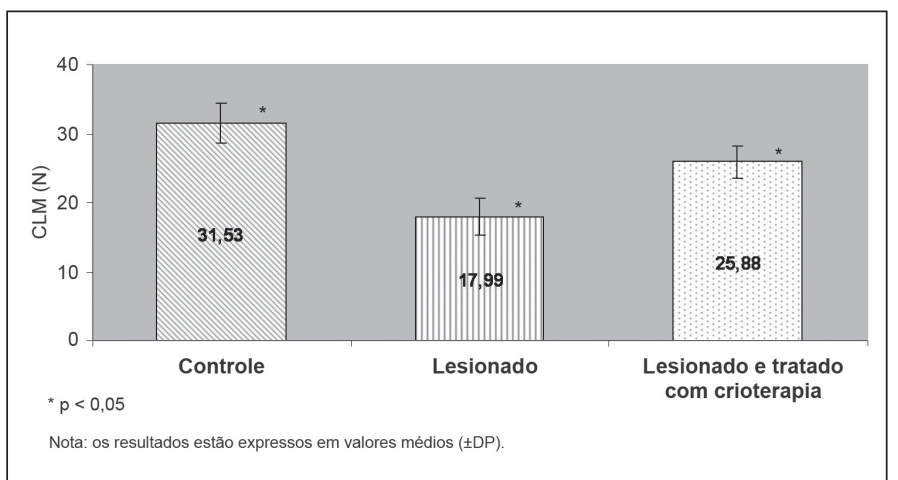

Gráfico 1. Representação gráfica das médias e desvios padrão da propriedade mecânica de carga no limite máximo (CLM).

\section{Alongamento no limite máximo (ALM)}

No que se refere à propriedade de ALM, os grupos C, L e LC apresentaram, respectivamente, os seguintes valores: $12,04 \pm 1,61 \times 10^{-3} \mathrm{~m}$; $9,19 \pm 2,20 \times 10^{-3} \mathrm{~m}$ e 10,07 $\pm 0,69 \times 10^{-3} \mathrm{~m}$ (gráfico 2).

Foi observada diferença estatística significativa, apenas entre os grupos $C$ e L $(p<0,01)$.

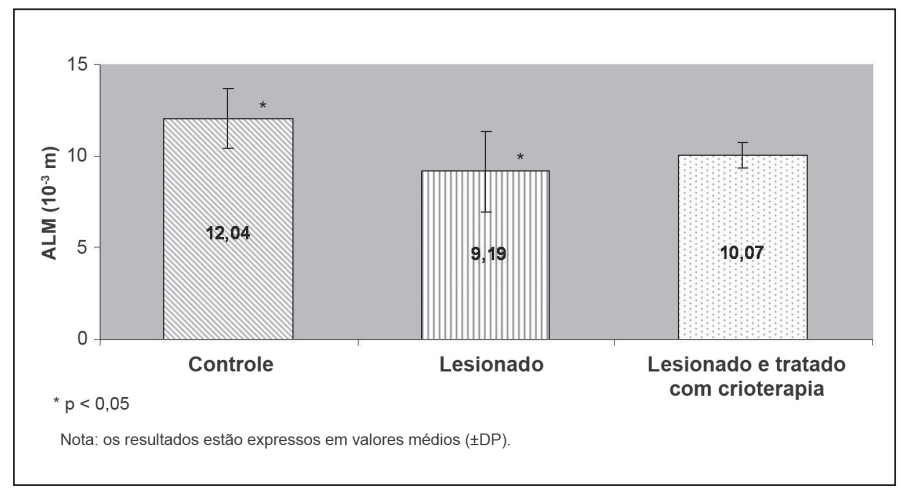

Gráfico 2. Representação gráfica das médias e desvios padrão da propriedade mecânica de alongamento no limite máximo (ALM).

\section{Rigidez (R)}

Quanto à rigidez $(R)$, os grupos $C$, L e LC apresentaram, respectivamente, os seguintes valores: 3,75 $\pm 0,30 \times 10^{3} \mathrm{~N} / \mathrm{m} ; 2,19 \pm 0,38 \times 10^{3} \mathrm{~N} / \mathrm{m}$ e 3,16 $\pm 0,33 \times 10^{3} \mathrm{~N} / \mathrm{m}$ (gráfico 3).

Houve diferença estatística significativa entre os três grupos: $C$ e L $(p<0,001)$; C e LC $(p<0,01)$; L e LC $(p<0,001)$.

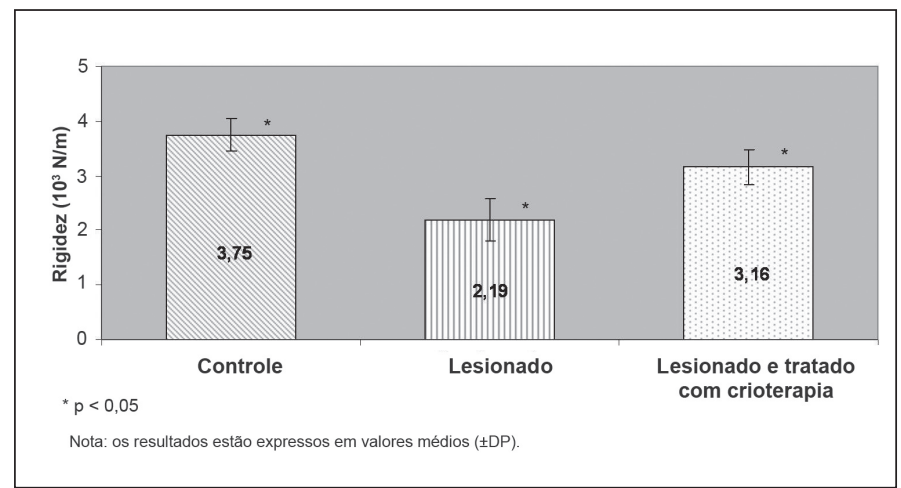

Gráfico 3. Representação gráfica das médias e desvios padrão da propriedade mecânica de rigidez (R).

\section{DISCUSSÃO}

Os achados deste trabalho mostraram que, enquanto os músculos lesionados sem intervenção apresentaram diminuição de todas as propriedades mecânicas analisadas, o tratamento com uma sessão de crioterapia acarretou efeitos biomecânicos positivos após seis dias, apesar de os animais submetidos ao tratamento não terem atingido os valores do grupo controle.

A aplicação de crioterapia no tecido muscular tem sido utilizada para obtenção de objetivos terapêuticos específicos ${ }^{(13)}$. Porém, havia uma lacuna na literatura científica no que se refere aos efeitos dessa terapia em propriedades mecânicas do tecido muscular. Dessa forma, a análise do ensaio mecânico de tração é interessante, pois simula cargas impostas à estrutura musculoesquelética em funcionamento, que é acometida por constante atuação de forças, principalmente tensão. 
Assim, a relevância dos resultados deste estudo está no fornecimento de importantes informações adicionais, que suportam as observações clínicas de que a crioterapia empregada no tratamento agudo da lesão muscular favorece a melhora da qualidade do tecido muscular esquelético.

Em nosso estudo, por meio da comparação entre os grupos $C$ e L, observamos que a lesão acarretou piora de todas as propriedades analisadas, o que é coerente com as observações clínicas e achados científicos que demonstram, por meio de diferentes tipos de análises, que a lesão muscular traumática induz alterações patológicas que ocasionam deterioração estrutural e funcional(7-8).

Quanto aos efeitos do tratamento da lesão aguda com crioterapia, foram observadas diferenças estatísticas significativas entre $L$ e $L C$ nas propriedades de CLM e rigidez. Porém, por meio da comparação entre C e LC, podemos observar que a sessão única crioterapia não foi capaz de recuperar as propriedades aos valores basais.

É importante ressaltar que reduções na rigidez, encontradas no grupo lesionado, devem ser levadas em consideração no processo de reabilitação, a fim de evitarmos complicações resultantes de sobrecarga muscular(23). Além disto, Jarvinen et al. ${ }^{(24)}$ relatam que essa é uma importante propriedade a ser estudada, pois sua redução indica que o músculo está alongando mais na presença de cargas menores, o que o torna mais suscetível a lesões.

Quanto às implicações da piora da propriedade de CLM dos grupos L e LC em relação ao controle, ressaltamos que músculos com essa propriedade reduzida, possivelmente, estão mais suscetíveis à ruptura, pois suportaram menores cargas. Em adendo, a diminuição da capacidade de alongamento antes da ruptura, avaliada por meio da propriedade de ALM, foi registrada apenas na comparação entre C e L. Apesar de $L C$ ter apresentado valor absoluto dessa propriedade superior ao grupo L, não foi constatada diferença estatística significativa.
Schaser et al. ${ }^{(6)}$ demonstraram, em ratos, que a crioterapia prolongada (seis horas) pós-lesão muscular, reduz a disfunção microvascular póstraumática, inflamação e enfraquecimento estrutural. Considerando que o enfraquecimento estrutural é vinculado à piora de propriedades mecânicas, nosso trabalho demonstrou que mesmo uma sessão mais curta, aplicada no tratamento agudo de uma contusão, pode exercer influência positiva na estrutura do tecido muscular.

Provavelmente, estão entre os fatores que contribuíram para a melhora das propriedades do grupo tratado com gelo: a redução da demanda de oxigênio e atividade metabólica celular, decorrentes da aplicação do frio, diretamente relacionadas à limitação da hipóxia secundária, decorrente da perfusão inadequada e conseqüente dano celular associado ao edema ${ }^{(6)}$.

Neste estudo, optamos pelo ensaio de tração, no qual a estrutura anatômica é fixada junto à máquina, preservando as características fisiológicas quanto à origem e inserção musculares. Isto é importante, pois a análise do tecido biológico como estrutura inteira reflete melhor a solicitação mecânica fisiológica.

Optamos por trabalhar com ratos, por serem de fácil manuseio, baixo custo e apresentarem estrutura musculoesquelética semelhante à do ser humano. Em adendo, a escolha do gastrocnêmio foi pertinente, pois é um músculo que trabalha sob condições de atividade física extrema, tendo risco aumentado para lesões ou rupturas(24). No entanto, os resultados obtidos neste estudo não podem ser totalmente extrapolados para seres humanos, devendo ser utilizados para nortear novas pesquisas.

Dessa forma, podemos concluir que a sessão de crioterapia por imersão, imediatamente após a lesão, promoveu melhora das propriedades mecânicas analisadas, sendo benéfica na fase de atendimento inicial em trauma agudo.

Todos os autores declararam não haver qualquer potencial conflito de interesses referente a este artigo.

\section{REFERÊNCIAS BIBLIOGRÁFICAS}

1. Olson JE, Stravino VD. A review of cryotherapy. Phys Ther 1972;52:840-53.

2. Cohn BT, Draeger RI, Jackson DW. The effects of cold therapy in the postoperative management of pain in patients undergoing anterior cruciate ligament reconstruction. Am J Sports Med 1989;17:344-9.

3. Grana WA. Physical agents in musculoskeletal problems: heat and cold therapy modalities. Instr Course Lect 1993:42:439-42.

4. Ernst E, Fialka V. Ice freezes pain? A review of the clinical effectiveness of analgesic cold therapy. J Pain Symptom Manage 1994;9:56-9.

5. Deal DN, Tipton J, Rosencrance E, Curl WW, Smith TL. Ice reduces edema. A study of microvascular permeability in rats. J Bone Joint Surg Am 2002;84-A:1573-8.

6. Schaser KD, Disch AC, Stover JF, Lauffer A, Bail HJ, Mittlmeier T. Prolonged superficial local cryotherapy attenuates microcirculatory impairment, regional inflammation, and muscle necrosis after closed soft tissue injury in rats. Am J Sports Med 2007;35:93-102.

7. Schaser KD, Vollmar B, Menger MD, Schewior L, Kroppenstedt SN, Raschke M, et al. In vivo analysis of microcirculation following closed soft-tissue injury. J Orthop Res 1999;17:678-85.

8. Jarvinen TA, Jarvinen TL, Kaariainen M, Kalimo H, Jarvinen M. Muscle injuries: biology and treatment. Am J Sports Med 2005;33:745-64.

9. Crisco JJ, Jokl P, Heinen GT, Connell MD, Panjabi MM. A muscle contusion injury model. Biomechanics, physiology, and histology. Am J Sports Med 1994;22:702-10.

10. Tidball JG. Inflammatory cell response to acute muscle injury. Med Sci Sports Exerc 1995;27:1022-32.

11. Huard J, Li Y, Fu FH. Muscle injuries and repair: current trends in research. J Bone Joint Surg Am 2002;84-A:822-32.

12. Buckwalter JA. Pharmacological treatment of soft-tissue injuries. J Bone Joint Surg Am 1995;77:1902-14.

13. Kubo K, Kanehisa H, Fukunaga T. Effects of cold and hot water immersion on the mechanical properties of human muscle and tendon in vivo. Clin Biomech (Bristol, Avon) 2005;20:291-300.
14. Hubbard TJ, Denegar CR. Does cryotherapy improve outcomes with soft tissue injury? J Athl Train 2004;39:278-9.

15. Cornwall MW. Biomechanics of noncontractile tissue. A review. Phys Ther 1984;64:1869-73.

16. Gould III JA. Biomecânica básica na terapia esportiva e ortopédica. In: Gould III JA, editor. Fisioterapia na ortopedia e na medicina do esporte. São Paulo: Manole, 1993;3-83.

17. CIOMS International Guiding Principles for Biomedical Research Involving Animals. Altern Lab Anim 1985;12:ii-

18. Stratton SA, Heckmann R, Francis R. Therapeutic ultrasound: it's effects on the integrity of a nonpenetrating wound. J Orthop Sports Phys Ther 1984;5:278-81.

19. Oliveira FB. O ultra-som terapêutico adicionado à imobilização gessada nas propriedades mecânicas da reparação muscular pós-trauma por mecanismo de impacto (Dissertação). Interunidades Bioengenharia: Universidade de São Paulo, 2004.

20. Sene GL. Influência do laser de baixa intensidade nas propriedades mecânicas do músculo gastrocnêmio submetido à lesão muscular por mecanismo de impacto (Dissertação). Interunidades Bioengenharia: Universidade de São Paulo, 2004.

21. Matheus JP, Gomide LB, Oliveira JGP, Volpon JB, Shimano AC. Efeitos da estimulação elétrica neuromuscular durante a imobilização nas propriedades mecânicas do músculo esquelético. Rev Bras Med Esporte 2007;13:55-9.

22. Minamoto VB, Grazziano CR, Salvini TF. Effect of single and periodic contusion on the rat soleus muscle at different stages of regeneration. Anat Rec 1999;254:281-7.

23. Carvalho CMM, Shimano AC, Volpon JB. Efeitos da imobilização e do exercício físico em algumas propriedades mecânicas do músculo esquelético. Rev Bras Eng Biomed 2002;18:65-73.

24. Jarvinen MJ, Einola SA, Virtanen EO. Effect of the position of immobilization upon the tensile properties of the rat gastrocnemius muscle. Arch Phys Med Rehabil 1992;73:253-7. 